\title{
Dietary sodium and potassium intake: knowledge, attitude and behaviour towards dietary salt intake among adults in Addis Ababa, Ethiopia
}

\author{
Semira Mitiku Saje ${ }^{1, *} \odot$, Bilal Shikur Endris ${ }^{1}$, Bikila Nagasa ${ }^{2}$, Genet Ashebir $^{2}$ and \\ Seifu Hagos Gebreyesus ${ }^{1}$ \\ 'Department of Nutrition and Dietetics, School of Public Health, Addis Ababa University, Addis Ababa 9086, \\ Ethiopia: ${ }^{2}$ Clinical Chemistry Laboratory, Ethiopian Public Health Institute, Addis Ababa, Ethiopia
}

Submitted 16 November 2019: Final revision received 29 August 2020: Accepted 16 September 2020: First published online 27 0ctober 2020

\begin{abstract}
Objective: The present study aimed to estimate the consumption of $\mathrm{Na}$ and $\mathrm{K}$ and to assess salt-related knowledge, attitude and behaviour among adults in Addis Ababa, Ethiopia.

Design: A community-based cross-sectional study was conducted. Estimates of $\mathrm{Na}$ and $\mathrm{K}$ intake were made using repeated multiple-pass 24-h dietary recall as well as using random urine. The usual intake of $\mathrm{Na}$ and $\mathrm{K}$ from the 24-h dietary recall was determined using the National Cancer Institute methodology. Estimated 24-h Na and $\mathrm{K}$ excretion was calculated using International Cooperative Study on Salt, Other Factors, and Blood Pressure and Tanaka formula.

Settings: Addis Ababa, the capital city of Ethiopia.

Participants: Individuals aged 20 years and above residing in the city.

Result: The mean $\mathrm{Na}$ and $\mathrm{K}$ intake estimated using the diet recall data was 3.0 (0.9) $\mathrm{g} / \mathrm{d}$ and $1.9(0.6) \mathrm{g} / \mathrm{d}$, respectively. Based on the urine analysis, the estimated mean $\mathrm{Na}$ and $\mathrm{K}$ intakes were $3.3(0.7) \mathrm{g} / \mathrm{d}$ and $1.9(0.4) \mathrm{g} / \mathrm{d}$, respectively. Moreover, the analysis showed that the mean $\mathrm{Na}$ : K ratio was 2.5 (1.4). The daily intake of $\mathrm{K}$ was below the recommended amount for all study participants. More than $98 \%$ and $90 \%$ of participants had an excess intake of $\mathrm{Na}$ and $\mathrm{Na}: \mathrm{K}$ ratio, respectively. Conclusion: We found a high prevalence of inadequate $\mathrm{K}$ intake as well as excess intake of $\mathrm{Na}$ resulting in an increased prevalence of excess $\mathrm{Na}$ :K ratio. Thus, interventions targeting to decrease $\mathrm{Na}$ intake and to increase $\mathrm{K}$ intake are needed.
\end{abstract}

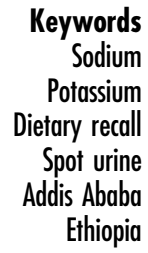

$\mathrm{Na}$ and $\mathrm{K}$ are essential nutrients that are needed for the maintenance of total body fluid volume, acid and electrolyte balance and normal cell function. Urinary excretion is the primary mechanism for maintaining body homoeostasis ${ }^{(1-3)}$. Dietary $\mathrm{Na}$ consumption depends on the cultural context and dietary habits of a population. $\mathrm{Na}$ can be found in common table salt and naturally in a variety of foods, such as milk, meat and shellfish. It is often found in high amounts in processed foods such as bread, crackers, processed meats and snack foods. $\mathrm{K}$ is commonly found in a variety of unrefined foods, especially fresh fruits, vegetables and beans ${ }^{(4,5)}$. Thus, a diet high in processed foods and low in fresh fruits and vegetables is often high in $\mathrm{Na}$ and low in $\mathrm{K}^{(6-9)}$.

The WHO recommends a Na intake of $<2 \mathrm{~g} / \mathrm{d}$ (equivalent to $5 \mathrm{~g}$ salt/d) and intake of $\mathrm{K}$ to be at least $3.5 \mathrm{~g} / \mathrm{d}$ in adults to reduce blood pressure and risk of CVD, stroke and $\mathrm{CHD}^{(4,10)}$. Despite these recommendations, $\mathrm{Na}$ intake around the world is more than physiological need. Most adult populations have a mean $\mathrm{Na}$ intake of $>2 \cdot 3 \mathrm{~g} / \mathrm{d}^{(5,10)}$. On the contrary, K consumption was less than the recommended level ${ }^{(11)}$. If an individual consumes $\mathrm{Na}$ and $\mathrm{K}$ at the levels recommended in the WHO guideline, the ratio of $\mathrm{Na}: \mathrm{K}$ would be approximately one to one, which is considered beneficial for health ${ }^{(12)}$. However, most populations around the world consume a ratio of Na:K of two to one or more ${ }^{(13)}$.

Findings from the International Cooperative Study on Salt, Other Factors, and Blood Pressure and the International Study on Macronutrients and Blood Pressure studies indicated a positive association between 
$\mathrm{Na}$ intake and body $\mathrm{Na}: \mathrm{K}$ ratio and blood pressure in multiethnic populations ${ }^{(14,15)}$. On the other hand, reduced $\mathrm{K}$ consumption has been associated with hypertension and CVD. Appropriate consumption levels could be protective against these conditions ${ }^{(12)}$. The ratio of the two nutrients is an important factor in CVD and mortality ${ }^{(16,17)}$. As Na consumption rises, increased consumption of $\mathrm{K}$ may be even more beneficial. Because in addition to other benefits, it can mitigate the negative effects of excess $\mathrm{Na}$ consumption on blood pressure ${ }^{(18)}$.

In 2014, CVD was attributed to $24 \%$ of adult deaths in the Ethiopian capital city Addis Ababa ${ }^{(19)}$. Another study reported a $22.6 \%$ prevalence of hypertension in Addis Ababa, while national prevalence was $15 \cdot 6 \%{ }^{(20)}$.

Two types of knowledge are required for consumers to make informed choices about their intake $\mathrm{e}^{(21,22)}$. The first is declarative knowledge, also known as knowledge of 'what is' (i.e. awareness of things and processes) or 'know that' knowledge (e.g. consumers need to know the recommended level of salt intake and the health risks of high salt intakes). The second is procedural knowledge, or 'know how' knowledge. Procedural knowledge is about practical skills - how to carry out certain tasks. For example, how to choose a lower salt product by comparing food label information and how to reduce the amount of salt used in the cooking by using herbs and spices ${ }^{(23)}$.

The WHO global action plan for the prevention and control of non-communicable diseases identifies a $25 \%$ reduction in premature mortality from CVD, a $25 \%$ reduction in raised blood pressure and a $30 \%$ reduction in mean population salt intake as targets for $2025^{(24)}$. In Ethiopia, the current $\mathrm{K}$ intake level and its ratio with $\mathrm{Na}$ were unknown, which plays a great role in achieving these goals. The present study aimed to evaluate $\mathrm{Na}$ and $\mathrm{K}$ intake and salt-related knowledge, attitude and behaviour among adult populations of Addis Ababa.

\section{Methods}

\section{Study area}

The study was conducted in Addis Ababa, the capital city of Ethiopia. Addis Ababa is found with an altitude of $2300 \mathrm{~m}$ and is located at $901^{\prime} 48^{\prime \prime} \mathrm{N}$ with a subtropical highland climate. The city has a total area of $527 \mathrm{~km}^{2}$ and a population density of $5165 \mathrm{~km}^{2}$. The city is organised into three levels of administration: city government, sub-cities and district administrations. Based on the 2007 national Census, Addis Ababa had a total projected population size of 3243514 in 2016. Among them, $54 \%$ were females ${ }^{(25)}$. Residents per capita income per year was 1364 US dollars, which was twice that of the national average ${ }^{(26)}$.

According to the national food consumption survey, cereals and legumes are the highest proportion of food groups consumed by women and men in Addis Ababa, accounting for $63.9 \%$ for women and $57 \cdot 1 \%$ for men ${ }^{(27)}$.
The availability of factory processed salt at the household level was estimated at $85 \%$ across the country ${ }^{(28)}$.

\section{Study design}

A community-based cross-sectional study design was employed, with the study conducted between March and April 2018.

\section{Sampling and study population}

The sample size was calculated using a formula for a single population mean ${ }^{(29)}$. The following assumptions were employed to calculate the required sample size; mean and SD for $\mathrm{K}$ intake at $1.46 \mathrm{~g} /$ person per $\mathrm{d}$ and $0.8 \mathrm{~g} /$ person per $\mathrm{d}$, respectively ${ }^{(30)}$, desired degree of precision at $0 \cdot 12 \mathrm{~g} /$ person per $\mathrm{d}$ and $95 \%$ of CI, 1.5 design effect and a contingency of $10 \%$ for non-respondent. Consequently, 294 households were adequate for the current study.

A multi-stage stratified sampling technique was applied to recruit study subjects. First, the ten administrative subcities were stratified into three groups (least, medium and most developed) based on socio-economic indicators obtained from the 2016 Ethiopian household consumptionexpenditure survey ${ }^{(31)}$. We randomly selected one sub-city from each stratum.

Second, the calculated sample size was allocated to the three strata proportional to their number of households. Third, we applied a simple random sampling method to select households using a sampling frame obtained from local authorities. Medically diagnosed hypertension and diabetes mellitus patients were excluded from the study because of the potential alteration on their $\mathrm{Na}$ and $\mathrm{K}$ intake due to medication and diet restriction.

\section{Data collection}

We trained and engaged fourteen female data collectors and three supervisors for the data collection. Four days of training were given to the research team. The training included a briefing about the study, detailed discussion on the questionnaire, anthropometry measurements, dietary data collection, urine sample collection and ethical issues. Small group discussions and demonstrations were part of the training.

Interviewer-based face to face data collection was conducted. During the household visits, the research team explained the aim of the study, and verbal informed consent was obtained before data collection.

\section{Measurements}

Socio-demographic and economic characteristics

The socio-demographic and economic status of the study participants were assessed using a questionnaire adopted from Ethiopian Demographic and Health Survey ${ }^{(32)}$. 


\section{Twenty-four-hour diet recall}

An interactive, multiple-pass 24-h dietary recall questionnaire adapted and validated for use in developing countries $^{(29)}$ was used to collect dietary intake. In order to precisely estimate the portion size of foods and drinks consumed, we used a food weighing scale, pictures of fruits and vegetables as well as calibrated locally available labelled cups, bowls, spoons and serving spoons. Participants were asked to put an equivalent amount of food they ate when actual food was available in the house. Dietary intake was weighted at the household of the respondent and for shared foods, and the respondents were asked to estimate the portion they ate by using the equipment. Discretionary salt added during eating was asked and estimated using a pinch, salt shaker and food weighing scale. For purchased foods, the price, brand name, and weight or size on the label was recorded together with the number of items consumed.

The dietary recall was repeated in randomly selected 90 households using different interviewers. The repeated data collection was done on a different non-consecutive day than the first to adjust for the day-to-day variation on nutrient intakes ${ }^{(33)}$.

\section{Urine collection}

Five-millilitre random urine was collected on site with a labelled additive-free tube. The collected random urine sample from the field was taken to the Ethiopian Public Health Institute clinical chemistry laboratory and refrigerated at $2-8{ }^{\circ} \mathrm{C}$ until the next day for analysis.

\section{Anthropometric data}

Height and weight measurements were taken to estimate 24-h electrolyte excretion from random urine. We used a locally constructed stadiometer with a precision of $0.1 \mathrm{~cm}$ to measure height. The weight of the participants was measured using a digital weighing scale, which has a capacity of $150 \mathrm{~kg}$ and a precision of $0 \cdot 1 \mathrm{~kg}$.

Knowledge, attitude and behaviour about dietary salt Data on knowledge, attitude and behaviour related to dietary salt among the study population were collected using questionnaires adopted from WHO and other literature ${ }^{(34-36)}$. Knowledge questions included the daily maximum recommended intake of salt, sources of salt and the relationship between high salt intake and health problems. Questions to assess attitude included the perception of own salt consumption and perceived importance of lowering salt intake. Salt-related behaviour was evaluated using questions such as behaviour of adding salt and taking actions to lower salt intake.

\section{Data management and analysis}

Non-dietary data were checked for completeness and entered into Epi data version $3 \cdot 1$ and exported to Stata 14 software for analysis. The normality of continuous variables was assessed by evaluating histograms, normally distributed data are presented as mean (SD) and skewed data presented as median (interquartile range: 25th-75th), and categorical variables were expressed as a percentage.

\section{Calculating sodium and potassium content of the diet}

We used Ethiopian and Tanzanian food composition tables and dietary database of nutri-survey to calculate $\mathrm{Na}$ and $\mathrm{K}$ content of foods and drinks. Nutrient values of mixed dishes were calculated from recipes, and information on the missing foods was taken from substitutes (estimation from similar foods). Nutrient labelling was used to analyse the nutrient composition of purchased food. The complied food composition table was entered into a software package nutri-survey to create a dietary database and to calculate intake per individual per $\mathrm{d}$. Outliers were checked visually using scatterplot ${ }^{(37)}$. None of the measurements were excluded.

We employed the National Cancer Institute methodology to estimate the usual $\mathrm{Na}$ and $\mathrm{K}$ intake. The National Cancer Institute methodology was preferred because it employs statistical modelling to account for intake variability. Assumptions of this model include 24-h dietary data are unbiased (but not error-free) and random within- and between-person variation (normally distributed, with a common variance and independent from those of other people). Skewed distributions of intakes were handled with transformations. The method estimates average daily intakes by considering the effect of covariates, which helps to estimate the population mean, usual intake closer to the true value and percentage of the population with usual intakes below/above cut-off points ${ }^{(38,39)}$.

\section{Urine analysis}

The collected urine sample was vortexed, reduced to a sample cup and analysed using Cobas 6000 (c501) analyser. Urinary $\mathrm{Na}$ and $\mathrm{K}$ were determined by using the ionselective electrode method, and urinary creatinine was measured by using the enzymatic method.

Estimated 24-h Na and K excretion was calculated from spot urine $\mathrm{Na}$, $\mathrm{K}$ and creatinine values adjusted for age, sex, height, weight and BMI using a formula developed by International Cooperative Study on Salt, Other Factors, and Blood Pressure ${ }^{(40)}$ and Tanaka ${ }^{(41)}$.

Salt intake per $\mathrm{d}$ was estimated by multiplying $\mathrm{Na}$ intake per $\mathrm{d}$ by 2.5 according to the WHO recommendation ${ }^{(10)}$.

\section{Prevalence of inadequate potassium intake and excess} salt, sodium and sodium:potassium ratio

We estimated the prevalence of inadequate $\mathrm{K}$ intake among the study population by comparing intake values with the least recommended value $(3.5 \mathrm{~g} / \mathrm{d})$. Prevalence of excess $\mathrm{Na}$ and excess salt intake was calculated by comparing intake values with the recommended value of $2 \mathrm{~g}$ $\mathrm{Na} / \mathrm{d}$ and $5 \mathrm{~g}$ salt/d, respectively. Similarly, the prevalence of excess $\mathrm{Na}$ to K intake was calculated by comparing with one to one ratio ${ }^{(4,10)}$. 


\section{Result}

A total of 294 households were approached for the study. We had a response rate of $97.3 \%$ ( $n$ 286). Two urine samples were discarded because the urine analysing machine could not calculate creatinine and $\mathrm{K}$ amount for an unknown reason. Ninety households were interviewed twice for dietary evaluation which results in a total of 386 interviews.

Table 1 shows the socio-demographic characteristics of the respondents. The majority (54.9\%) of the study participants were female. Most of the study participants (83.1\%) were in the age range of 20-39 years, with a median age of 30 years. Two-thirds of the participants (69\%) were married. Family size ranged from 1 to 11 with a median value of 4 per household.

\section{Salt, sodium, potassium and sodium:ratio intake} measured using 24-b diet recall and urine

Table 2 shows mean values of anthropometry measurements, salt, $\mathrm{Na}$ and $\mathrm{K}$ intake estimated from both the diet recall data and spot urine collection. The mean BMI measurement was $22.9(4.1) \mathrm{kg} / \mathrm{m}^{2}$. Mean Na intake estimated using the diet recall data and urine analysis was $3.0(0.9) \mathrm{g} / \mathrm{d}$ and $3.3(0.7) \mathrm{g} / \mathrm{d}$, respectively. Besides, the mean $\mathrm{K}$ intake estimated using the diet recall data was $1.9(0.6) \mathrm{g} / \mathrm{d}$, while the mean $\mathrm{K}$ intake estimated using 24-h urinary excretion was $1.9(0.4) \mathrm{g} / \mathrm{d}$. The analysis also showed that the mean Na:K ratio of 2.5 (1.4). The 24-h dietary intake data showed a lower mean salt intake of $7.5(2.2) \mathrm{g} / \mathrm{d}$ than the urine analysis.

\section{Prevalence of inadequate potassium intake and excess salt, sodium and sodium:potassium ratio}

Table 3 shows the prevalence of inadequate $\mathrm{K}$ intake and excess intake of salt, $\mathrm{Na}$ and $\mathrm{Na}: \mathrm{K}$ ratio. Based on the 24-h diet recall as well as the spot urine, the daily intake of $\mathrm{K}$ was below the recommended amount, i.e. below $3.5 \mathrm{~g} / \mathrm{d}$ for all study participants. Based on the 24-h diet recall and the spot urine, $99.7 \%$ and $98.2 \%$ of participants had an excess

Table 1 Socio-demographic characteristics of study participants in Addis Ababa, Ethiopia, 2018

\begin{tabular}{|c|c|c|c|c|c|c|}
\hline \multirow[b]{2}{*}{ Variables } & \multicolumn{2}{|c|}{ Male $(n 128)$} & \multicolumn{2}{|c|}{ Female (n 156) } & \multicolumn{2}{|c|}{ Total (n 284) } \\
\hline & Frequency & $\%$ & Frequency & $\%$ & Frequency & $\%$ \\
\hline \multicolumn{7}{|l|}{ Age in years } \\
\hline $20-29$ & 71 & $55 \cdot 5$ & 66 & $42 \cdot 3$ & 137 & $48 \cdot 2$ \\
\hline $30-39$ & 37 & $28 \cdot 9$ & 62 & $39 \cdot 7$ & 99 & 34.9 \\
\hline $40-49$ & 15 & $11 \cdot 7$ & 19 & $12 \cdot 2$ & 34 & 11.9 \\
\hline $50-59$ & 3 & 2.3 & 5 & 3.2 & 8 & $2 \cdot 8$ \\
\hline$\geq 60$ & 2 & 1.6 & 4 & $2 \cdot 6$ & 6 & $2 \cdot 2$ \\
\hline \multicolumn{7}{|l|}{ Educational status } \\
\hline College/university & 26 & $20 \cdot 3$ & 16 & $10 \cdot 2$ & 42 & $14 \cdot 8$ \\
\hline Secondary (9-12) & 54 & $42 \cdot 2$ & 43 & $27 \cdot 6$ & 97 & $34 \cdot 1$ \\
\hline Primary (1-8) & 41 & 32 & 60 & 38.5 & 101 & $35 \cdot 6$ \\
\hline Read and/or write & 1 & 0.8 & 3 & 1.9 & 4 & 1.4 \\
\hline Illiterate & 6 & $4 \cdot 7$ & 34 & $21 \cdot 8$ & 40 & $14 \cdot 1$ \\
\hline \multicolumn{7}{|l|}{ Marital status } \\
\hline Single & 52 & $40 \cdot 6$ & 28 & $17 \cdot 9$ & 80 & $28 \cdot 2$ \\
\hline Married & 75 & $58 \cdot 6$ & 121 & $77 \cdot 6$ & 196 & 69 \\
\hline Widowed & 0 & - & 5 & $3 \cdot 2$ & 5 & $1 \cdot 7$ \\
\hline Separated/divorced & 1 & 0.8 & 2 & $1 \cdot 3$ & 3 & $1 \cdot 1$ \\
\hline \multicolumn{7}{|l|}{ Religion } \\
\hline Orthodox & 99 & $77 \cdot 3$ & 133 & $85 \cdot 3$ & 232 & $81 \cdot 7$ \\
\hline Muslim & 15 & $11 \cdot 7$ & 11 & 7 & 26 & $9 \cdot 2$ \\
\hline Protestant & 13 & $10 \cdot 2$ & 11 & 7 & 24 & $8 \cdot 4$ \\
\hline Catholic/Jehovah witnesses & 1 & 0.8 & 1 & 0.6 & 2 & 0.7 \\
\hline \multicolumn{7}{|l|}{ Occupation } \\
\hline Government employee & 13 & $10 \cdot 2$ & 18 & 11.5 & 31 & $10 \cdot 9$ \\
\hline Private & 74 & $57 \cdot 8$ & 21 & $13 \cdot 5$ & 95 & 33.4 \\
\hline Merchant & 13 & $10 \cdot 2$ & 9 & $5 \cdot 8$ & 22 & $7 \cdot 8$ \\
\hline Student & 12 & $9 \cdot 4$ & 7 & 4.5 & 19 & $6 \cdot 7$ \\
\hline Daily labourer & 4 & $3 \cdot 1$ & 5 & $3 \cdot 2$ & 9 & $3 \cdot 2$ \\
\hline Unemployed & 12 & $9 \cdot 4$ & 96 & $61 \cdot 5$ & 108 & 38 \\
\hline \multicolumn{7}{|l|}{ Family size ( $n$ 281) } \\
\hline $1-3$ & - & - & - & - & 95 & 33.8 \\
\hline $4-5$ & - & - & - & - & 116 & $41 \cdot 3$ \\
\hline $9-11$ & - & - & - & - & 70 & 24.9 \\
\hline \multicolumn{7}{|c|}{ Average monthly household income ( $n$ 262) } \\
\hline$\leq 1000$ ETB & - & - & - & - & 80 & $30 \cdot 5$ \\
\hline 1200-2000 ETB & - & - & - & - & 91 & $34 \cdot 8$ \\
\hline >2000 ETB & - & - & - & - & 91 & $34 \cdot 7$ \\
\hline
\end{tabular}

ETB, Ethiopian birr. 
Table 2 Salt, sodium and potassium intakes and their ratio measured from 24-h diet recall and spot urine in Addis Ababa, Ethiopia, 2018

\begin{tabular}{lrc}
\hline Variables & Mean & SD \\
\hline Height $(\mathrm{cm})$ & 161.9 & 9 \\
Weight $(\mathrm{kg})$ & 59.8 & 11.2 \\
$\mathrm{BMI}\left(\mathrm{kg} / \mathrm{m}^{2}\right)$ & 22.9 & 4.1 \\
Estimated usual intake using 24-h recall & & \\
$\mathrm{K}(\mathrm{g})$ & 1.9 & 0.6 \\
$\mathrm{Na}(\mathrm{g})$ & 3.0 & 0.9 \\
$\mathrm{NaCl}(\mathrm{g})$ & 7.5 & 2.2 \\
Estimated 24-h excretion from urine & & \\
$\mathrm{K}(\mathrm{g})$ & 1.9 & 0.4 \\
$\mathrm{Na} \mathrm{(g)}$ & 3.3 & 0.7 \\
$\mathrm{NaCl}(\mathrm{g})$ & 8.2 & 1.8 \\
$\mathrm{Na}: \mathrm{K}$ & 2.5 & 1.4 \\
\hline
\end{tabular}

Table 3 Prevalence of an inadequacy of potassium and excess salt, sodium and $\mathrm{Na}: \mathrm{K}$ intake measured from 24-h diet recall and spot urine in Addis Ababa, Ethiopia, 2018

\begin{tabular}{|c|c|c|c|c|}
\hline Variables & Frequency & $\begin{array}{l}\text { Prevalence } \\
\text { of inadequate } \\
\text { intake }\end{array}$ & $\begin{array}{l}\text { Prevalence } \\
\text { of excess } \\
\text { intake }\end{array}$ & $95 \% \mathrm{Cl}$ \\
\hline \multicolumn{5}{|l|}{ 24-h diet recall } \\
\hline $\mathrm{Na} \geq 2(\mathrm{~g})$ & 283 & - & 99.7 & - \\
\hline $\mathrm{K}<33.5(\mathrm{~g})$ & 284 & 100 & - & - \\
\hline \multicolumn{5}{|c|}{ 2- $\mathrm{h}$ urine excretion } \\
\hline $\mathrm{Na} \geq 2(\mathrm{~g})$ & 279 & - & $98 \cdot 2$ & $95 \cdot 8,99 \cdot 3$ \\
\hline $\mathrm{K}<3.5(\mathrm{~g})$ & 284 & 100 & - & - \\
\hline $\mathrm{Na}: \mathrm{K} \geq 1$ & 256 & - & $90 \cdot 1$ & $86 \cdot 1,93 \cdot 1$ \\
\hline
\end{tabular}

intake of $\mathrm{Na}$, respectively. Also, $90 \cdot 1 \%$ of the participants had excess Na:K ratio.

\section{Salt-related knowledge, attitude and behaviour}

Table 4 shows the knowledge, attitude and behaviour of study participants about dietary salt. Only five (1.8\%) of participants knew that there is a recommended maximum amount for daily salt consumption. More than half $(56.3 \%$ and $58.1 \%)$ of the respondents perceived that their salt intake is 'just the right amount' and responded positively to the importance of lowering salt intake, respectively. More than $75 \%$ of the study participants do not add salt at the table and $90 \cdot 1 \%$ knew about the effect of increased salt consumption on health.

\section{Discussion}

This study aimed to estimate the level of $\mathrm{K}$ and $\mathrm{Na}$ intake and to assess salt-related knowledge, attitude and behaviour among adult populations of Addis Ababa. Face-to-face interview was conducted using standardised questionnaire. Twenty-four-hour diet recall data and urine samples were taken. The result showed a high prevalence of
Table 4 Salt-related knowledge, attitude and behaviour of study participants in Addis Ababa, Ethiopia, 2018

\begin{tabular}{|c|c|}
\hline Variables & Percent $(n$ 284) \\
\hline \multicolumn{2}{|l|}{ Knows about daily salt intake limit } \\
\hline Knows & 1.8 \\
\hline Don’t know & $98 \cdot 2$ \\
\hline \multicolumn{2}{|l|}{ Source of salt } \\
\hline Salt added during cooking and/or serving & 77.5 \\
\hline Processed food & $2 \cdot 1$ \\
\hline Natural food source & $6 \cdot 7$ \\
\hline Don’t know & 13.7 \\
\hline \multicolumn{2}{|l|}{ Knows about salt and a health problem } \\
\hline Knows & $90 \cdot 1$ \\
\hline Don’t know & 9.9 \\
\hline \multicolumn{2}{|l|}{ Health problems related to high salt diet $(n 256)^{*}$} \\
\hline High blood pressure & $87 \cdot 1$ \\
\hline Osteoporosis & $2 \cdot 3$ \\
\hline Stomach cancer & $22 \cdot 7$ \\
\hline Kidney stone & $41 \cdot 4$ \\
\hline None of the above & $2 \cdot 3$ \\
\hline All of the above & 1.6 \\
\hline Don’t know & 1.9 \\
\hline \multicolumn{2}{|l|}{ Perception of own salt consumption } \\
\hline Far too much & 0.7 \\
\hline Too much & $8 \cdot 8$ \\
\hline Just the right amount & $56 \cdot 3$ \\
\hline Too little & $25 \cdot 7$ \\
\hline Far too little & $5 \cdot 3$ \\
\hline Don’t know & $3 \cdot 2$ \\
\hline \multicolumn{2}{|l|}{ Perceived importance of lowering salt intake } \\
\hline Not at all important & $6 \cdot 3$ \\
\hline Somewhat important & $6 \cdot 3$ \\
\hline Neutral & 5 \\
\hline Important & $58 \cdot 1$ \\
\hline Very important & $24 \cdot 3$ \\
\hline \multicolumn{2}{|l|}{ Adding salt to food during serving } \\
\hline Never & $77 \cdot 8$ \\
\hline Rarely & $14 \cdot 8$ \\
\hline Sometimes & $7 \cdot 4$ \\
\hline \multicolumn{2}{|l|}{ Adding salt to food during cooking } \\
\hline Always & $80 \cdot 3$ \\
\hline Often & $17 \cdot 6$ \\
\hline Sometimes & $2 \cdot 1$ \\
\hline \multicolumn{2}{|l|}{ Taking actions to control salt intake } \\
\hline Action taken & $67 \cdot 6$ \\
\hline Action not taken & $32 \cdot 4$ \\
\hline \multicolumn{2}{|l|}{ Actions taken to control salt intake $(n 192)^{*}$} \\
\hline Avoid/minimise processed foods & 21.9 \\
\hline Look at the salt or $\mathrm{Na}$ labels on food & 1.6 \\
\hline Do not add salt at the table & $42 \cdot 7$ \\
\hline Buy low salt/Na alternatives & 7.8 \\
\hline Do not/decrease the amount during cooking & $30 \cdot 7$ \\
\hline Use spices other than salt when cooking & $2 \cdot 1$ \\
\hline Avoid eating out & $2 \cdot 8$ \\
\hline
\end{tabular}

*Multiple answers were possible.

inadequate $\mathrm{K}$ intake. Moreover, a high prevalence of excess intake was found for $\mathrm{Na}$ and its ratio with $\mathrm{K}$. More than half of the respondents perceived that their salt intake is 'just the right amount'. The majority of the respondents (80.3\%) added salt during cooking always, and more than two-thirds of the respondents reported that they are taking actions to lower their salt intake.

This study found $3.0 \mathrm{~g} / \mathrm{d}$ mean consumption of $\mathrm{Na}$ estimated from 24-h diet recall data and this is higher than the recommended amount. A consistent finding was reported 
from a study done in the Cape Verde men population ${ }^{(42)}$. Our finding is not consistent with a previous study done in Addis Ababa, which found $4.0 \mathrm{~g} / \mathrm{d}$ mean $\mathrm{Na}$ intake ${ }^{(43)}$. This inconsistency may be because we used a different food composition table. Ethiopian food composition table is not complete in quantifying $\mathrm{Na}$ and $\mathrm{K}$ content of all food types. This forced us to borrow a different country's food composition table which was available in our respective year of study. Different amount of intake is reported in previous studies done in other countries ${ }^{(44-46)}$. This difference is attributed to the difficulty of quantifying discretionary salt intake, incomplete or/and inaccurate food composition table, demerits of dietary recall difference in intake and diversity of diet.

The current study found a relatively lower amount of $\mathrm{Na}$ consumption from diet recall than the urine finding. This was because diet recalls most of the time results in underestimation of intake. Salt/Na intake depends on the amount of food intake especially in foods that undergo some alteration (non-raw foods). Thus, if there is an underestimation of intake, it is likely to get low figures for salt/ $\mathrm{Na}$ consumption $^{(47,48)}$.

$\mathrm{Na}$ consumption estimated from urinary excretion in the current study was $3.3 \mathrm{~g} / \mathrm{d}$. This finding is consistent with a previous study done in the urban settings of Ethiopia, which used a similar method and found $3.3 \mathrm{~g} / \mathrm{d}$ mean $\mathrm{Na}$ consumption. The proportion of the population above the recommended value was $98.2 \%$ and $97.5 \%$ in our study and the previous study, respectively ${ }^{(49)}$. The consistent finding also reported from a study in South Africa, which found $3.3 \mathrm{~g} / \mathrm{d}$ mean $\mathrm{Na}$ intake ${ }^{(50)}$. A slight difference is observed in the prevalence of excess $\mathrm{Na}$ intake in Benin. This may be because the study done in Benin included urban and rural parts of the country ${ }^{(30)}$. A systematic review conducted in sub-Saharan African countries reported that salt/Na intake in the rural setting is lower than in urban settings. This can be explained by westernisation of cities and towns. Because salty packed foods and fast foods high in salt are more accessible in urban areas than in rural areas $^{(51)}$. Inconsistent higher findings also reported from China, this may be explained by their culture of consuming salty sauces besides the use of cooking salt ${ }^{(46,52)}$.

$\mathrm{K}$ intake from 24-h diet recall in our study was $1.9 \mathrm{~g} / \mathrm{d}$, and none of the intakes were adequate. This finding is much lower than the least daily recommended amount. It is because in Ethiopia the consumption of fruit and vegetables is very low. We found that only two participants (0.7\%) had adequate fruit and vegetable intake, which are the main sources of $\mathrm{K}$. Another study found a $0.9 \%$ prevalence of fruit and/or vegetable consumption in urban areas of Ethiopia ${ }^{(53)}$. This might be because the cultivation of fruits and vegetables in Ethiopia was sub-optimal ${ }^{(54)}$. A relatively higher intake of $\mathrm{K}$ was reported from the Cape Verdean study. This was because their daily consumption of fruits and vegetables was higher than our study ${ }^{(42)}$. A 3.1 and $3.2 \mathrm{~g} / \mathrm{d}$ mean $\mathrm{K}$ intake was reported from South Korea for the age group of 19-39 years and 40-59 years, respectively, they justify that this intake comes from white rice, kimchi, vegetable and fruits, which are not common foods in the Ethiopian setting ${ }^{(55)}$. A similar finding was reported from China which used three consecutive 24-h diet data ${ }^{(46)}$.

Our study reported $1.9(0.4) \mathrm{g} / \mathrm{d}$ mean $\mathrm{K}$ excretion, and all values were below the recommended amount. A similar finding is reported from Mozambique $1.9(0.8) \mathrm{g} / \mathrm{d}$ with an inadequate prevalence of $96 \cdot 3 \%{ }^{(56)}$. Similar findings to our study were also reported from existing literature ${ }^{(52,57-59)}$. Relatively higher $\mathrm{K}$ intake was reported from the subSaharan country Benin, this may be due to the inclusion of rural communities in the study. Hence, the availability of fresh fruits, vegetables and beans is relatively high in the rural area especially if there is home gardening. Another explanation could be as participants in Benin's study were told to abstain from going to work and to stay in health care centres on the day of urine collection. This might have altered the participants' dietary habits ${ }^{(30)}$. The $\mathrm{K}$ intake reported from New Zealand was higher than the current study; this can be explained because they did not exclude hypertensive patients. Even though they did not mention the type of medication they took, some hypertensive drugs alter the $\mathrm{K}$ excretion ${ }^{(60)}$.

The mean consumption of Na:K ratio was $2.5(1.4) \mathrm{g} / \mathrm{d}$. The prevalence of excess intake was $90 \cdot 1 \%$ compared with a one to one ratio. Consumption of $\mathrm{Na}$ and $\mathrm{K}$ at one to one ratio is considered to be beneficial for health ${ }^{(12)}$. Our finding was consistent with previous studies ${ }^{(46,57)}$. However, inconsistent findings were also reported from existing studies ${ }^{(30,55,60)}$. This inconsistency is attributed to the above-mentioned reasons for each nutrients difference in intake, which affects the ratio.

Our study finding showed a higher Na:K ratio which puts the population at risk of hypertension and CVD. The ratio of the two nutrients is more influential than the effect of each nutrient independently. It has been suggested that individuals with diets that are low in $\mathrm{K}$ are particularly vulnerable to the hypertensive effects of a high $\mathrm{Na}$ intake. In evaluating results, a high amount of $\mathrm{Na}$ finding only may not be as severe as high $\mathrm{Na}: \mathrm{K}$ ratio. Because a high $\mathrm{Na}$ intake might be accompanied by a good $\mathrm{K}$ intake which gives a lower ratio of the two nutrients ${ }^{(16-18,61-64)}$.

Knowledge of study participants on maximum daily salt consumption $(5 \mathrm{~g} / \mathrm{d})$ was much lower than other country studies $^{(65,66)}$. Since there was nothing done in the study setting to create awareness about dietary salt consumption, it is likely to get a lower figure than the others. Nine out of ten individuals knew that a high salt diet could cause a serious health problem. Among them, majorities mentioned blood pressure. This finding is comparable with published studies $^{(34,35,67)}$.

A consistent finding was reported on the perception of own salt intake to be 'just the right amount' ${ }^{(68)}$ and too much or far too much ${ }^{(67)}$. Though we found a high prevalence of excess salt intake, a lower proportion of the 
population believed that their intake was high. This finding was not in concordance with previous studies ${ }^{(34,65,66,69)}$. The potential reason might be due to the presence of salt reduction initiation in other countries' study.

The majority of participants agreed on the importance of lowering salt intake. As a result, $67.7 \%$ took actions to lower their intake. This finding was higher than the previous study done in Ethiopia. Actions taken to lower salt intake in the two studies were somehow different. This may attribute to the variation in the study setting in which the current study included only the urban population $^{(67)}$.

Our finding on salt usage during cooking was consistent with a previous study in Ethiopia. However, there was a discrepancy in salt usage at the table before eating. This could be because the previous study included salty sauce usage besides the discretionary salt added at the table, which was not included in the current study ${ }^{(67)}$. Our finding was consistent with the study finding of Angola and India, and the majority of participants stated that salt was always added in preparing food at home ${ }^{(35,69)}$.

The present study shall be interpreted with the following strengths and limitations. In this study, discretionary salt usage was quantified which helps us to get a good figure on the actual salt intake. A combination of biochemical and dietary assessment was used to assess $\mathrm{Na}$ and $\mathrm{K}$ intake, which decreases the effect of measurement error. We used the National Cancer Institute method to estimate the usual intake. This method considers factors affecting intake, which is helpful to have an estimate closer to the true value. Moreover, all days of the week were represented equally during data collection to adjust for dayto-day variation in nutrient intake. However, this study has limitations that need to be acknowledged. First, we used self-reported dietary data, which may be different from actual behaviour and may result in most of the time in underreporting. To overcome this problem, we used pictures and food weighing scales during portion size estimation and respondents were probed for snacks, fruits and outdoor consumption. Second, the Ethiopian food composition table is not complete regarding $\mathrm{Na}$ and $\mathrm{K}$ values of diet. This forced us to borrow values from another country's food composition table which decrease reliability of the dietary database. Third, we used spot urine to estimate $\mathrm{Na}$ and $\mathrm{K}$ consumption. It is known that spot urine analysis does not give a stable estimate at the individual level. But it was proved that it can provide a reliable estimate at the population level. Though validation studies support the use of spot urine at the population level, they also showed there could be an underestimation $^{(41,50)}$. Fourth, the formula we used to estimate 24-h electrolyte excretion from spot urine was not validated in our country. Even though it is not validated in our country, we used formulas which had a relatively good result during validation studies among heterogeneous population including Africa.

\section{Conclusion}

In conclusion, we found a high prevalence of inadequate $\mathrm{K}$ intake and a high prevalence of excess $\mathrm{Na}$ intake. The ratio of the two nutrients is higher than what is recommended to be beneficial for health, which put the population at risk of hypertension and CVD. Salt-related knowledge, attitude and behaviour were found to be low as many participants were unaware of their high salt intake. Thus, an intervention targeting to decrease $\mathrm{Na}$ intake and increase $\mathrm{K}$ intake is needed. Decreasing salt consumption and increasing fruits and vegetable consumption could be an effective way. Because salt and fruits and vegetables are the main sources of $\mathrm{Na}$ and $\mathrm{K}$, respectively.

\section{Acknowledgements}

Acknowledgements: We would like to thank Mr Demewoz Haile, Mr Feyissa Chala, Mr Masresha Tesema and $\mathrm{Mr}$ Meseret Werede for their technical support. We would like to extend our compliment to data collectors and study participants. We would not have done this without you. Financial support: This research received no specific grant from any funding agency, commercial or not-for-profit sectors. Conflict of interest: There are no conflicts of interest. Authorship: S.M.S. initiated the research, prepared the proposal, conducted the research, entered the data, analysed the data, interpreted the findings and wrote the manuscript. S.H.G. and B.S.E. were involved in initiating the research, interpreting the findings and reviewing the manuscript. B.N.O. and G.A.B. were involved in urine sample analysis. All authors read and approved the final manuscript. Ethics of human subject participation: This study was conducted according to the guideline laid down in the Declaration of Helsinki, and all procedures involving research study participants were approved by the Research Ethical Committee of School of Public Health, Addis Ababa University and Addis Ababa regional health bureau. Written informed consent was obtained from all subjects.

\section{References}

1. Young DB (2001) Role of Potassium in Preventive Cardiovascular Medicine. Boston: Kluwer Academic Publishers.

2. Holbrook JT, Patterson KY, Bodner JE et al. (1984) Sodium and potassium intake and balance in adults consuming self-selected diets. Am J Clin Nutr 40, 786-793.

3. Medical Dictionary (2003) Sodium. http://medicaldictionary.thefreedictionary.com/sodium (accessed September 2017).

4. World Health Organization (2012) Guideline: Potassium Intake for Adults and Children. Geneva: WHO.

5. Brown IJ, Tzoulaki I, Candeias V et al. (2009) Salt intakes around the world: implications for public health. Int $J$ Epidemiol 38, 791-813. 
6. Wu Leung W, Butrum R, Chang F et al. (1972) Food Composition Table for Use in East Asia. Atlanta: FAO and US Department of Health.

7. Centers for Disease Control and Prevention (2011) Vital signs: food categories contributing the most to sodium consumption in United States from 2007-2008. Morb Mortal Wkly 61, 92-98.

8. Ni Mhurchu C, Capelin C, Dunford EK et al. (2011) Sodium content of processed foods in the United Kingdom: analysis of 44000 foods purchased by 21000 households. Am J Clin Nutr 93, 594-600.

9. Webster JL, Dunford EK \& Neal BC (2010) A systematic survey of the sodium contents of processed foods. $\mathrm{Am} \mathrm{J}$ Clin Nutr 91, 413-420.

10. World Health Organization (2012) Guideline: Sodium Intake for Adults and Children. Geneva: WHO.

11. Van Mierlo LA, Greyling A, Zock PL et al. (2010) Suboptimal potassium intake and potential impact on population blood pressure. Arch Intern Med 170, 1501-1502.

12. World Health Organization (2003) Diet, Nutrition and the Prevention of Chronic Diseases. Joint WHO/FAO Expert Consultation. WHO Technical Report. Series no. 916. Geneva: WHO.

13. Elliott P (2007) Sodium Intakes around the World. Background Document Prepared for the Forum and Technical Meeting on Reducing Salt Intake in Populations (Paris 5-7 October 2006). Geneva: WHO.

14. Intersalt: an international study of electrolyte excretion and blood pressure (1988) Results for 24 hour urinary sodium and potassium excretion. BMJ 297, 319-328.

15. Zhao L, Stamler J, Yan LL et al. (2004) Blood pressure differences between northern and southern Chinese: role of dietary factors: the international study on macronutrients and blood pressure. Hypertension 43, 1332-1337.

16. Cook NR, Obarzanek E, Cutler JA et al. (2009) Joint effects of sodium and potassium intake on subsequent cardiovascular disease: the trials of hypertension prevention follow-up study. Arch Intern Med 169, 32-40.

17. Yang Q, Liu T, Kuklina EV et al. (2011) Sodium and potassium intake and mortality among US adults: prospective data from the Third National Health and Nutrition Examination Survey. Arch Intern Med 171, 1183-1191.

18. Whelton PK, He J, Cutler JA et al. (1997) Effects of oral potassium on blood pressure. Meta-analysis of randomized controlled clinical trials. J Am Med Assoc 277, 1624-1632.

19. Misganaw A, Mariam DH \& Araya T (2012) The double mortality burden among adults in Addis Ababa, Ethiopia, 2006-2009. Prev Chronic Dis 9, E84.

20. Abebe B, Terefe G, Kassahun A et al. (2017) The hidden magnitude of raised blood pressure and elevated blood glucose in Ethiopia: a call for initiating community based NCDs risk factors screening program. Ethiop J Health Dev 31, 362-369.

21. Kemm J (1991) Health education and the problem of knowledge. Health Prom Int 6, 291-296.

22. Worsley A (2002) Nutrition knowledge and food consumption: can nutrition knowledge change food behaviour? Asia Pac J Clin Nutr 11, Suppl. 3, S579-S585.

23. Sarmugam R \& Worsley A (2014) Current levels of salt knowledge: a review of the literature. Nutrients $\mathbf{6}, 5534-5559$.

24. World Health Organization (2013) Global Action Plan for the Prevention and Control of Noncommunicable Diseases 2013-2020. Geneva: WHO

25. Central Statistical Agency (2008) Summary and Statistical Report of the 2007 Population and Housing Census. Addis Ababa: CSA, UNFPA \& UNDP.

26. United Nations Human Settlements Programme (2017) The State of Addis Ababa. Nairobi: UN Habitat.

27. Ethiopian Public Health Institute (EPHI) (2013) Ethiopia National Food Consumption Survey. Addis Ababa: EPHI.
28. Ethiopian Public Health Institute (EPHI) (2016) Ethiopian National Micro Nutrient Survey. Addis Ababa: EPHI.

29. Gibson RS \& Ferguson EL (2008) An Interactive 24-Hour Recall for Assessing the Adequacy of Iron and Zinc Intakes in Developing Countries. Washington, DC and Cali: HarvestPlus Technical Monograph 8.

30. Carmelle M, Dismand H, Corine H et al. (2017) Dietary sodium and potassium intakes Data from urban and rural areas. Nutrition 33, 35-41.

31. Central Statistics Agency (2016) The 2015/16 Ethiopian Household Consumption - Expenditure (HCE) Survey. Addis Ababa: CSA.

32. Central Statistical Agency (2017) Ethiopia Demographic and Health Survey 2016. Addis Ababa, Maryland \& USA: CSA and ICF.

33. IOM (2000) Dietary Reference Intakes: Applications in Dietary Assessment. Washington, DC: National Academy Press.

34. Grimes CA, Kelley SJ, Stanley S et al. (2017) Knowledge, attitudes and behaviours related to dietary salt among adults in the state of Victoria, Australia 2015. BMC Public Health 17, 532 .

35. Johnson C, Mohan S, Rogers K et al. (2017) The association of knowledge and behaviours related to salt with 24-h urinary salt excretion in a population from North and South India. Nutrients 9, 144.

36. World Health Organization \& Pan American Health Organization (2010) Protocol for Population Level Sodium Determination in 24-hour Urine Samples. Washington, DC \& USA: WHO \& PAHO.

37. Diet assessment primer (2018) - learn more about outliers. https://dietassessmentprimer.cancer.gov/learn/outliers.html (accessed July 2018).

38. Usual Dietary Intakes (2018) - The NCI Method EGRP/DCCP/ NCI/NIH. https://epi.grants.cancer.gov/diet/usualintakes/ method.html (accessed July 2018).

39. Measurement error webinar series (2018) - EGRP/DCCP/ $\mathrm{NCI} / \mathrm{NIH}$. https://epi.grants.cancer.gov/events/measurementerror/ (accessed July 2018).

40. Elliott P, Brown IJ Dyer AR et al. (2013) Response to "quantifying urine sodium excretion". Am J Epidemiol 177, $1196-1198$

41. Tanaka T, Okamura T, Miura K et al. (2002) A simple method to estimate population 24-h urinary sodium and potassium excretion using a casual urine specimen. J Hum Hypertens 16, 97-103.

42. Daniela A, Zélia S, Miguel A et al. (2018) Low potassium and high sodium intakes: a double health threat to Cape Verdeans. BMC Public Health 18, 995.

43. Abuye C, Berhane Y, Akalu G et al. (2007) Prevalence of goiter in children 6-12 years of age in Ethiopia. Food Nutr Bull 28, 391-398.

44. Santos JA, Webster J, Land MA et al. (2017) Dietary salt intake in the Australian population. Public Health Nutr 20, 1887-1894.

45. Vandevijvere SVOH (2008) Sodium intake in the Belgian population research limitations and policy implications. Arch Public Health 66, 187-195.

46. Shufa D, Ne iman A, Batis C et al. (2014) Understanding the patterns and trends of sodium intake, potassium intake, and sodium to potassium ratio and their effect on hypertension in China. Am J Clin Nutr 99, 334-343.

47. Freedman LS, Commins JM, Moler JE et al. (2015) Pooled results from 5 validation studies of dietary self-report instruments using recovery biomarkers for potassium and sodium intake. Am J Epidemiol 181, 473-487.

48. Rhodes DG, Murayi T, Clemens JC et al. (2013) The USDA automated multiple-pass method accurately assesses population sodium intakes. Am J Clin Nutr 97, 958-964.

49. Feyissa C, Yewondwossen T, Kissi M et al. (2017) Urinary sodium excretion and determinates among adults in 
Ethiopia: findings from National STEPS survey. Ethiop $J$ Health Dev 34, 370-377.

50. Bianca S, Schutte AE, Marike C et al. (2017) Monitoring the South African population's salt intake: spot urine v. $24 \mathrm{~h}$ urine. Public Health Nutr 21, 480-488.

51. Oyebode O, Oti S, Chen YF et al. (2016) Salt intakes in subSaharan Africa: a systematic review and meta-regression. Popul Health Metr 14, 1.

52. Liuxia Y, Xiaolei G, Huicheng W et al. (2016) Populationbased association between urinary excretion of sodium, potassium and its ratio with albuminuria in Chinese. Asia Pac J Clin Nutr 25, 785-797

53. Terefe G, Kassahun A, Tefera T et al. (2017) Low fruit and vegetable intake and its associated factors in Ethiopia: a community based cross sectional NCD steps survey. Ethiop J Health Dev 31, 355-361.

54. Tsegaye D, Ahmed A \& Dilnesaw Z (2009) Availability and consumption of fruits and vegetables in nine regions of Ethiopia with special emphasis to vitamin A deficiency. Ethiop J Health Dev 23, 216-222.

55. Haeng-Shin L, Duffey KJ \& Popkin BM (2013) Sodium and potassium intake patterns and trends in South Korea. J Hum Hypertens 27, 298-303.

56. Ana Q, Damasceno A, Neusa J et al. (2017) Urinary sodium and potassium excretion and dietary source of sodium in Maputo, Mozambique. Nutrients 9, 830.

57. Keiko A, Ken U, Yuki S et al. (2014) Estimation of sodium and potassium intakes assessed by two $24 \mathrm{~h}$ urine collections in healthy Japanese adults: a nation wide study. Br J Nutr 112, 1195-1205.

58. Masoud M, Mohammadhossien S, Mahdieh N et al. (2014) Sodium and potassium intake of urban dwellers: nothing changed in Yazd, Iran. J Health Popul Nutr 32, 111-117.

59. Samuel A, Adewole A \& Solomon K (2018) Increased urinary sodium excretion is associated with systolic blood pressure in first degree relatives of hypertensive patients in Ibadan, Southwestern Nigeria. Pan Afri Med J 31, 168.

60. Rachael M, Julia E, Sheila W et al. (2015) Balancing sodium and potassium: estimates of intake in a New Zealand adult population sample. Nutrients 7, 8930-8938.

61. Kawasaki T, Itoh K \& Kawasaki M (1998) Reduction in blood pressure with a sodium-reduced, potassium- and magnesium-enriched mineral salt in subjects with mild essential hypertension. Hypertens Res 21, 235-243.

62. Chang HY, Hu YW, Yue CS et al. (2006) Effect of potassiumenriched salt on cardiovascular mortality and medical expenses of elderly men. Am J Clin Nutr 83, 1289-1296.

63. Nancy R, Cook EO, Jeffrey AC et al. (2009) Joint effects of sodium and potassium intake on subsequent cardiovascular disease. Arch Intern Med 169, 32-40.

64. Perez V \& Chang ET (2014) Sodium-to-potassium ratio and blood pressure, hypertension, and related factors. Adv Nutr 5, 712-741.

65. Zhang J, Xu A-q, Ma J-x et al. (2013) Dietary sodium intake: knowledge, attitudes and practices in Shandong Province, China, 2011. PLoS One 8, e58973.

66. Nasreddine L, Akl C, Al-Shaar L et al. (2014) Consumer knowledge, attitudes and salt-related behavior in the Middle-East: the case of Lebanon. Nutrients 6, 5079-5102.

67. Ethiopian Public Health Institute (EPHI) (2016) Ethiopia Steps Report on Risk Factors for Non Communicable Disease and Prevalence of Selected NCDS. Addis Ababa: EPHI.

68. Rajib M, Rajib Chandra S, Palash Chandra B et al. (2017) Knowledge, attitude and behaviour towards dietary salt intake among Bangladesh medical and non medical students. Int J Perception Public Health 2, 1.

69. Magalhaes P, Sanhangala EJ, Dombele IM et al. (2015) Knowledge, attitude and behaviour regarding dietary salt intake among medical students in Angola. Cardiovasc J Afr 26, 57-62. 